Fuzzy Sets and Systems, Vol. 131, Issues No. 1, Oct. 2002, pp. 107-120.

\title{
Structural Analysis of Audit Evidence Using Belief Functions
}

\author{
Rajendra P. Srivastava \\ Ernst \& Young Professor and Director \\ Ernst \& Young Center for Auditing Research and Advanced Technology \\ Division of Accounting and Information Systems \\ School of Business \\ The University of Kansas \\ Phone: (785) 864-7590 \\ Fax: (785) 864-5328 \\ (rsrivastava@ku.edu)
}

and

Hai Lu

Division of Accounting and Information Systems

School of Business

The University of Kansas 


\title{
Structural Analysis of Audit Evidence Using Belief Functions
}

\author{
ABSTRACT \\ This article performs two types of analysis using Dempster-Shafer theory of belief functions for \\ evidential reasoning. The first analysis deals with the impact of the structure of audit evidence \\ on the overall belief at each variable in the network, variables being the account balance to be \\ audited, the related transaction streams, and the associated audit objectives. The second analysis \\ deals with the impact of the relationship (logical "and" and "algebraic relationship") among \\ various variables in the network on the overall belief. For our first analysis, we change the \\ evidential structure from a network to a tree and determine its impact.
}




\section{Structural Analysis of Audit Evidence Using Belief Functions}

\section{INTRODUCTION}

This article has two main objectives. First objective is to perform a sensitivity analysis on the structure of audit evidence when planning and evaluating an audit in the belief-function framework $[7,8,9,10]$. The second objective is to perform a sensitivity analysis on the relationship among various variables in the evidential network. It is well known that, in general, audit evidence forms a network structure of variables, variables being the accounts on the financial statements, transaction streams, management assertions and the related audit objectives $[4,12,13,16,17]$. The network structure exists because one item of evidence provides support to more than one variable in the network.

It is expected that inclusion of interdependencies among the evidence would provide a more efficient audit. To illustrate this point let us consider the audit of accounts receivable. Assume that the account balance is fairly stated if management assertions, 'Existence' and 'Valuation', are met. Assume further that the auditor confirms a sample of accounts receivable to determine whether the two assertions are met. After evaluating the confirmation results, the auditor decides to assign, say, 0.8 degree of support for 'Existence' and 0.6 degree of support for 'Valuation'. A higher level of support for Existence compared to the level of support to Valuation could be because of some mathematical errors in the customers' accounts. What will be the combined level of support in the above case for the accounts receivable balance being fairly stated? Well, if we assume the two items of evidence to be independent, which 
would be the case if a tree instead of a network structure is considered, the total belief would be only 0.48 (the product of the two numbers). However, if we consider the network structure, i.e., the interdependence of the evidence, then it will be 0.6 , a much higher level of support [16].

Although the network structure provides a more efficient audit program, this efficiency is achieved at a cost of computational complexities. In this article, we would like to investigate the level of impact on the overall belief of all the variables in the network if the structure was changed to a tree, i.e., if all the items of evidence were assumed independent, especially when there is so much uncertainty in the input values of the assurance.

In regards to the second objective, we know that both the auditing researchers and practitioners have treated the relationships among the accounts in the transaction streams and the accounts on the balance sheet to be an 'and' relationship $[4,5]$. This relationship implies that if the accounts in the transaction stream are fairly stated then the related account on the balance sheet will be fairly stated. For example, we know that the ending accounts receivable balance $\left(A / R_{E}\right)$ is equal to the beginning accounts receivable balance $\left(A / R_{B}\right)$ plus sales on credit minus cash receipts on credit sales $(C / R)$ minus any sales returns and cash discounts. Suppose that sales discounts and cash discounts are not significant. Then, the ending accounts receivable balance can be written as:

$$
\mathrm{A} / \mathrm{R}_{\mathrm{E}}=\mathrm{A} / \mathrm{R}_{\mathrm{B}}+\text { Sales }-\mathrm{C} / \mathrm{R} \text {. }
$$

An 'and' relationship implies that $\mathrm{A} / \mathrm{R}_{\mathrm{E}}$ is fairly stated if and only if Sales and $\mathrm{C} / \mathrm{R}$ are fairly stated. This relationship is true in only one direction, that is, when Sales 
and $C / R$ are fairly stated, $A / R_{E}$ is fairly stated. However, if $A / R_{E}$ is fairly stated then it is not necessary that Sales and $\mathrm{C} / \mathrm{R}$ are fairly stated, but an 'and' relationship dictates it so. Srivastava [14] has developed a relational node, 'and-neor', to represent an algebraic relationship among variables in the belief-function framework. We want to investigate the impact of such relationships among the variables in a network while planning and evaluating an audit. We will use the network structure developed by Srivastava, Dutta, and Johns [16] for the health care industry for the present study.

The remainder of the paper is divided into four sections. Section 2 discusses the audit process and the audit risk model. Section 3 presents a belief function representation of categorical and algebraic relationships among variables. Section 4 analyzes the overall belief on each variable when network structure is changed to a tree structure. Section 5 presents a sensitivity analysis of the changes in the relationship among variables from 'and' to an algebraic relationship, 'and-neor', for both network and tree structures. Finally, Section 6 provides a summary and conclusion of the results.

\section{THE AUDIT PROCESS AND AUDIT RISK MODEL}

An audit is the process of accumulating, evaluating, and aggregating evidence to determine whether the financial statements (FS) present fairly the financial position of the company in accordance with GAAP (Generally Accepted Accounting Principles). The management of the company being audited has the responsibility for preparing FS in accordance with GAAP. In doing so, the management is making certain assertions about the numbers being reported in the FS. These assertions are called management assertions. Statement on Auditing Standards No. 31 [1] classifies them into five categories: 
'Existence or Occurrence', 'Completeness', 'Rights and Obligation', 'Valuation or Allocation', and 'Presentation and Disclosure' [see 4 for definitions].

An account balance is fairly stated when all its management assertions have been met. And, the FS are fairly stated when all the accounts are fairly stated. In order to facilitate accumulation of evidence to determine whether each of the management assertions is met for each account, the AICPA has developed its own a set of objectives called audit objectives, e.g., Existence, Completeness, Rights and Obligation, Accuracy, Classification, Cutoff, Detail Tie-in, and Presentation and Disclosure [4]. These objectives are closely related to the management assertions. For example, the audit objectives: Existence, Completeness, and Rights and Obligation, respectively, correspond to the management assertions: Existence or Occurrence, Completeness, Rights and Obligation. The audit objectives: Accuracy, Classification, Detail Tie-in, and RealizableValue relate to the 'Valuation' assertion because they all deal with the valuation of the account balance on the FS.

The above conceptual framework suggests that the auditor has to collect sufficient evidence to make sure that each assertion for each account is met and consequently each account is fairly stated, leading to the fair presentation of the whole FS. Leslie et. al [5], while discussing the assertion based approach to auditing, expanded the above concept further by explicitly bringing in the indirect evidence to bear upon the balance sheet account through specific assertions. As discussed earlier, we know that the ending balance of accounts receivable $\left(A R_{E}\right)$ is equal to the beginning balance $\left(A R_{B}\right)$ plus the sales (S) for the period minus the cash receipts $(\mathrm{C} / \mathrm{R})$ on the sales (assuming that there are 
no sales returns and cash discounts). However, in terms of the specific assertions, especially for 'Existence' and 'Completeness', we get the following relationships [5]:

$\mathrm{AR}($ Existence $)=\mathrm{AR} B($ Existence $)+\mathrm{S}($ Existence $)-\mathrm{C} / \mathrm{R}($ Completeness $)$

$\mathrm{AR}($ Completeness $)=\mathrm{AR} B($ Completeness $)+\mathrm{S}($ Completeness $)-\mathrm{C} / \mathrm{R}($ Existence $)$

For the rest of the assertions, all the accounts in the above relationship have the same assertion. The above relationships suggest that if the auditor wants to determine whether the 'Existence' assertion is met for the ending balance of accounts receivable (ARE), then he or she can look for items of evidence that directly bear on the 'Existence' assertion of ARE such as confirmations of selected accounts from customers. At the same time, indirect evidence from sales 'Existence' and cash receipts 'Completeness' should be considered. That is, if sales exist (not overstated) and cash receipts on sales are complete (not understated) then the existence assertion of the accounts receivable balance is met. It is important to note that this detailed relationship between balance sheet accounts (e.g., cash, accounts receivable, inventory, etc.) and the transaction streams (e.g., cash receipts, cash disbursements, sales, purchases etc.) helps the auditor perform an efficient audit [5]. Recently, the AICPA has incorporated the above approach through Statement on Auditing Standards No. 55 [3] and also auditing textbooks have started discussing these concepts [4]. However, it is not clear how the above concepts can be integrated into the audit risk model of SAS 47.

The audit risk model of SAS 47 [2] is used in practice to plan an audit in terms of determining the nature and extent of evidence to collect. This model is a multiplicative 
model usually consisting of four risk terms: Inherent Risk (IR), Control Risk (CR), Analytical Procedure Risk (APR), and Detection Risk (DR). This model implies that the auditor will fail to detect material errors in an account and give a clean opinion when all of the following conditions are met: (1) material misstatements do exist in the account (1 $\geq$ IR $>0$ ), (2) internal controls fail to detect and correct such errors $(1 \geq C R>0)$, (3) the auditor's analytical procedures fail to detect them $(1 \geq$ APR $>0)$, and (4) the auditor's tests of details fail to detect them $(1 \geq \mathrm{TDR}>0)$. A multiplicative model makes intuitive sense. However, it does not allow the incorporation of interdependencies among items of evidence and interrelationships among accounts and transaction streams, and the related audit objectives or management assertions. We will use the general framework of evidential reasoning under uncertainty using belief functions for audit decisions. Such an approach allows one to take into consideration all the relevant item of evidence whether that piece of evidence bears on the financial statement level, the account level, the transaction stream level, the individual audit objective level, or the management assertion level of the account.

Another problem with the audit risk model of SAS 47 is the use of probabilities to model the auditor's judgment about risks. According to SAS 47, if the auditor does not want to depend on the inherent factors, then he or she should set the inherent risk equal to $1(\mathrm{IR}=1)$. If we interpret this number as probability then we conclude that it is certain that the account is materially misstated. But this is not what the auditor has in mind when he or she decides not to depend on inherent factors for the audit. The auditor's feeling is represented better by a belief-function plausibility of 1 for material misstatements. A plausibility value of 1 implies that the auditor lacks evidence based on 
inherent factors. Srivastava and Shafer [17] analyze this issue further and state the following:

... the auditor may believe, on the basis of inherent factors, that the account is fairly stated and yet be unwilling to rely on these factors past a certain point. In this case, the auditor may, as SAS No. 47 suggests, assign a value less than the maximum, say 70 percent, to inherent risk. If interpreted in probability terms, this number says that the inherent factors give a 30 percent chance that the account is not materially misstated and a 70 percent chance that it is materially misstated. This suggests that the evidence is negative, contrary to the auditor's intuition.

A belief function interpretation of the risks in the audit risk model makes more intuitive sense than the probability interpretation. In fact, as shown by Srivastava and Shafer [11, 17], the risks in the audit risk model can be interpreted as belief-function plausibilities provided all the evidence is positive. However, an evidential reasoning approach of audit decision making using a network structure of evidence and belief functions allows one to consider all types of evidence, positive, negative, and mixed, and also the interdependencies among the evidence and among the accounts. Such an approach is used in the present study.

\section{CATEGORICAL AND LINEAR ALGEBRAIC RELATIONSHIPS IN BELIEF FUNCTIONS}

In this section, we want to show how categorical and linear algebraic relationships among variables can be modeled in the belief-function framework. We need such relationships in belief functions in order to combine evidence in a network of variables under the belief-function framework. In particular, representing linear algebraic relationships among variables becomes essential if we want to propagate belief functions in a network of variables that are related through such relationships. For example, as mentioned earlier, the ending balance of the accounts receivable is equal to the beginning 
balance plus the sales minus the cash receipts for the period. We will first describe categorical relationships such as 'and', 'or', 'eor' (exclusive or), and 'neor' (not exclusive or) in both probability and belief functions frameworks, and then represent a linear algebraic relationship in terms of belief functions. Srivastava [14] has used Srivastava and Cogger's [15] algorithm to develop general belief-function representations of categorical and uncertain relationships among variables.

Assume we have three variables: A, B and C. An 'and' relationship between C, and $\mathrm{A}$ and $\mathrm{B}$ implies that $\mathrm{C}$ is true if and only if $\mathrm{A}$ and $\mathrm{B}$ are true $(\mathrm{C}=\mathrm{A} \cap \mathrm{B})$. Such a relationship will allow only the following possible set of values ${ }^{1}$ for the variables: $\{a b c$, $a \sim b \sim c, \sim a b \sim c, \sim a \sim b \sim c\}$. One can express the above relationship through the following conditional probabilities:

$$
\begin{gathered}
\mathrm{P}(\mathrm{c} \mid \mathrm{ab})=1, \mathrm{P}(\sim \mathrm{c} \mid \mathrm{ab})=0, \\
\mathrm{P}(\mathrm{c} \mid \mathrm{a} \sim \mathrm{b})=0, \mathrm{P}(\sim \mathrm{c} \mid \mathrm{a} \sim \mathrm{b})=1, \\
\mathrm{P}(\mathrm{c} \mid \sim \mathrm{ab})=0, \mathrm{P}(\sim \mathrm{c} \mid \sim \mathrm{ab})=1, \\
\mathrm{P}(\mathrm{c} \mid \sim \mathrm{a} \sim \mathrm{b})=0, \mathrm{P}(\sim \mathrm{c} \mid \sim \mathrm{a} \sim \mathrm{b})=1 .
\end{gathered}
$$

In the belief-function framework the above relationship is represented by:

$$
\mathrm{m}(\{\mathrm{abc}, \mathrm{a} \sim \mathrm{b} \sim \mathrm{c}, \sim \mathrm{ab} \sim \mathrm{c}, \sim \mathrm{a} \sim \mathrm{b} \sim \mathrm{c}\})=1 .
$$

For an 'or' relationship between $\mathrm{C}$, and $\mathrm{A}$ and $\mathrm{B}$ (i.e., $\mathrm{C}=\mathrm{A} \cup \mathrm{B}$ ), we will have the following possible values: $\{a b c, a \sim b c, \sim a b c, \sim a \sim b \sim c\}$. This relationship implies that $\mathrm{C}$ is true when either both A and B are true or when any one of them is true, but it is false

${ }^{1}$ We represent the value of a variable, say A, by the lower case letter ' $a$ ' if it is true and by $\sim$ a if the value of $A$ is not true. 
when both $\mathrm{A}$ and $\mathrm{B}$ are false. In terms of probabilities, we can express the above relationship as:

$$
\begin{gathered}
\mathrm{P}(\mathrm{c} \mid \mathrm{ab})=1, \mathrm{P}(\sim \mathrm{c} \mid \mathrm{ab})=0, \\
\mathrm{P}(\mathrm{c} \mid \mathrm{a} \sim \mathrm{b})=1, \mathrm{P}(\sim \mathrm{c} \mid \mathrm{a} \sim \mathrm{b})=0, \\
\mathrm{P}(\mathrm{c} \mid \sim \mathrm{ab})=1, \mathrm{P}(\sim \mathrm{c} \mid \sim \mathrm{ab})=0, \\
\mathrm{P}(\mathrm{c} \mid \sim \mathrm{a} \sim \mathrm{b})=0, \mathrm{P}(\sim \mathrm{c} \mid \sim \mathrm{a} \sim \mathrm{b})=1 .
\end{gathered}
$$

The belief function representation is:

$$
\mathrm{m}(\{\mathrm{abc}, \mathrm{a} \sim \mathrm{bc}, \sim \mathrm{abc}, \sim \mathrm{a} \sim \mathrm{b} \sim \mathrm{c}\})=1 .
$$

An 'exclusive or (eor)' relationship between $\mathrm{C}$, and $\mathrm{A}$ and $\mathrm{B}$ implies that $\mathrm{C}$ is true only when either A is true or B is true but it is false when both A and B are either false or true. Such a relationship will allow only the following set of values: $\{a b \sim c, a \sim b c, \sim a b c$, $\sim \mathrm{a} \sim \mathrm{b} \sim \mathrm{c}\}$. The probability representation of this relationship is:

$$
\begin{gathered}
\mathrm{P}(\mathrm{c} \mid \mathrm{ab})=0, \mathrm{P}(\sim \mathrm{c} \mid \mathrm{ab})=1, \\
\mathrm{P}(\mathrm{c} \mid \mathrm{a} \sim \mathrm{b})=1, \mathrm{P}(\sim \mathrm{c} \mid \mathrm{a} \sim \mathrm{b})=0, \\
\mathrm{P}(\mathrm{c} \mid \sim \mathrm{ab})=1, \mathrm{P}(\sim \mathrm{c} \mid \sim \mathrm{ab})=0, \\
\mathrm{P}(\mathrm{c} \mid \sim \mathrm{a} \sim \mathrm{b})=0, \mathrm{P}(\sim \mathrm{c} \mid \sim \mathrm{a} \sim \mathrm{b})=1 .
\end{gathered}
$$

In the belief-function framework, the above relationship is represented by:

$$
\mathrm{m}(\{\mathrm{ab} \sim \mathrm{c}, \mathrm{a} \sim \mathrm{bc}, \sim \mathrm{abc}, \sim \mathrm{a} \sim \mathrm{b} \sim \mathrm{c}\})=1 .
$$

Let us now consider the 'and-neor' relationship. This relationship arises when we have three variables related through an algebraic relationship such as: $\mathrm{C}=\mathrm{A} \pm \mathrm{B}$. In this case, $\mathrm{C}$ is true when both A and B are true, and it is false when any one of them (A or B) is false but the other one is true. However, when both A and B are false, we do not know 
whether $\mathrm{C}$ is true or false because there could be off-setting errors that might make $\mathrm{C}$ true. This relationship is symmetric in all the three variables, as it should be, because they have the same relationship: $\mathrm{A}=\mathrm{B} \pm \mathrm{C}$, or $\mathrm{B}=\mathrm{A} \pm \mathrm{C}$. Moreover, simply knowing that $\mathrm{C}$ is true, we cannot say anything about the state of A or B because there could be infinitely many different values of A and B that can make C true. Such a relationship will only allow the following set of values: $\{a \mathrm{bc}, \mathrm{a} \sim \mathrm{b} \sim \mathrm{c}, \sim \mathrm{ab} \sim \mathrm{c}, \sim \mathrm{a} \sim \mathrm{bc}, \sim \mathrm{a} \sim \mathrm{b} \sim \mathrm{c}\}$. As one can see, these values are symmetric in all the three variables. Also, one can see that the above set of values is really the union of the values for 'and' and 'neor' relationships. The belief function representation of the above relationship is:

$$
\mathrm{m}(\{\mathrm{abc}, \mathrm{a} \sim \mathrm{b} \sim \mathrm{c}, \sim \mathrm{ab} \sim \mathrm{c}, \sim \mathrm{a} \sim \mathrm{bc}, \sim \mathrm{a} \sim \mathrm{b} \sim \mathrm{c}\})=1 .
$$

This relationship allows us to propagate beliefs in a network of variables with linear algebraic relationships. This type of situation is quite common in accounting. For

example, in the audit of an accounts receivable balance the auditor combines the evidence gathered for sales transactions and for cash receipts with the direct evidence for the ending balance of the accounts receivable from confirmations. 'and-neor' will help us combine such items of evidence in an evidential network.

\section{STRUCTURAL ANALYIS: NETWORK VERSUS TREE}

In this section, we discuss how the overall belief on each variable varies with the change in the evidential structure from a network to a tree of variables. Figure 1 along with Figures 1a-1c represents a network of variables for the audit of accounts receivable of a health care unit. These figures are taken from Srivastava, Dutta, and Johns [16]. As evidenced from Figure 1, since one item of evidence supports several variables, the evidential structure is a network. In order to perform our analysis, the evidential structure 
is changed from a network to a tree by assuming every item of evidence as independent, supporting only one variable. For example, if an item of evidence bears on two variables, then this evidence is broken into two items of evidence each supporting separate variables. Figure 2 represents such a structure which is obtained by changing the network structure in Figure 1 to a tree structure.

Figure 3 shows the overall belief on each variable with an 'and' relationship among the variables for the two structures: network and tree. For the base value of the input beliefs as used by Srivastava et. al [16], the change in the overall belief for each variable when a network is converted into a tree varies from a negative $2.5 \%$ at the account level to a negative $2.9 \%$ at the sub-transaction level (see Figure 3). When the base input values are decreased by $10 \%$, the overall belief is decreased by $0.94 \%$ at "Presentation \& Disclosure" and 1.86\% at "AR Existence \& Occurrence." At a decrease of $20 \%$ in the base values of the input beliefs, the overall belief decreased by $0.64 \%$ at "Presentation \& Disclosure" and 2.24\% at "Revenue Existence \& Occurrence." At a decrease of $30 \%$ in the base inputs, the overall belief decreased by $0.22 \%$ at "Presentation \& Disclosure" and $2.46 \%$ at "Accounts Receivable." It is interesting to note that even for positive increases in the base values, the change in the overall beliefs remain negative. These are important results and have practical implications. First, all the changes in the overall beliefs are quite small even when the changes in the input beliefs are large. This implies that a network structure can be replaced by a tree structure without any significant impact on the overall beliefs. Such an approximation will eliminate the computational complexities of propagating beliefs in a network [12,13] and allow auditors to use a simple spreadsheet approach to combine evidence in a tree [18]. 
Second, all changes in the overall beliefs are negative, irrespective of the changes in the input values. This result shows that a network structure with all its interrelationships is always more efficient than a tree structure where interrelationships are assumed to be nonexistent. However, this efficiency is not significant as evidenced from Figure 3.

Similar to Figure 3, Figure 4 shows the changes in the overall beliefs when the evidential structure is changed from a network to a tree with various levels of changes in the input beliefs for 'and-neor' relationships among those variables that are related through algebraic relationships. There is no significant change in the overall beliefs even though individual input beliefs vary from + or $-10 \%$ to + or $-30 \%$.

Figure 5 represent changes in the overall beliefs when the evidential structure changes from a network to a tree as various items of evidence are gathered in a sequence, starting from the items of evidence at the account level to items of evidence at the sub-transaction level. It is interesting to note that there is no significant change in the overall beliefs under the two structures as successive items of evidence are gathered in the prescribed sequence. However, if the evidence accumulation sequence was reversed then one would expect a significant difference in the overall beliefs under the two structures.

\section{SENSITIVITY ANALYSIS: 'AND' VERSUS 'AND-NEOR'}

In this section, we discuss how the overall beliefs under a network or a tree structure change as the relationships among certain variables are changed from 'and' to 'and-neor', an algebraic relationship. Tables 1 and 2, respectively, present the results for a network and a tree structure. Since the changes in the relationship occur at the transaction and sub-transaction levels (see Figures 1 and 2), the overall beliefs at those levels are the ones 
that are affected by the changes in the relationships (see Table 1 and 2). The maximum change occurs at the sub-transaction level. Also, as one can see from Table 1, there is almost no change in the overall beliefs when the input beliefs were increased by $10 \%$ or $20 \%$ from the base value. This is because the overall belief is already close to the maximum value 1 and no further increase can be expected as further increase in the input beliefs are made.

\section{SUMMARY AND CONCLUSIONS}

In general, it is well known that audit evidence forms a network of variables, variables being the account balances, audit objectives, accounts in the transaction stream and their audit objectives, and the financial statements as a whole. The audit process is basically accumulation, evaluation and aggregation of audit evidence. However, aggregation of audit evidence in a network becomes quite complex $[12,13]$. It requires computer programs such as “Auditor's Assistant” developed by Shafer, Shenoy, and Srivastava [6] for combining evidence in a network. It is shown here that the overall beliefs on variables of a network in an audit is not affected significantly by the change of the structure from a network to a tree. This has an important practical implication. Since there is no significant difference between the overall beliefs under the two structures, especially given the uncertainties in the input beliefs, assuming a tree structure for the evidence will be considerably efficient for computational complexities. The second type of sensitivity performed in the paper deals with the changes in the overall beliefs with changes in the relationships from 'and' to 'and-neor'. Again, no significant differences between the overall beliefs under the two relationships were observed, especially when all the evidence considered in the case has been aggregated. 


\section{REFERENCES}

[1] American Institute of Certified Public Accountants. Statement on Auditing Standards, No, 31: Evidential Matter, New York: AICPA, 1980. . Statement on Auditing Standards, No, 47: Audit Risk and Materiality in Conducting an Audit. New York: AICPA, 1983.

[3] . Statement on Auditing Standards, No. 55: Consideration of the Internal Control Structure in a Financial Statement Audit. New York: AICPA, 1988.

[4] Arens, A.A., and J.K. Loebbecke, Auditing: An Integrated Approach. Englewood Cliffs, NJ: Prentice-Hall, 1996.

[5] Leslie, D.A., and S. J. Aldersley, D.J. Cockburn, and C.J. Reiter. "An assertionbased approach to auditing (discussant's remarks)". Proceedings of the 1986 Touche Ross/University of Kansas Symposium on Auditing Problems. Lawrence, KS: School of Business, University of Kansas, 1986, 31-67.

[6] Shafer, G., P.P. Shenoy, and R. P. Srivastava, "Auditor's Assistant: A knowledge engineering tool for audit decisions", Proceedings of the 1988 Touche Ross/University of Kansas Symposium on Auditing Problems. Lawrence, KS: School of Business, University of Kansas, 1988, 61-84.

[7] Shafer, G., A Mathematical Theory of Evidence. Princeton University Press, 1976.

[8] Shafer, G., and R.P. Srivastava, "The bayesian and belief-function formalisms: A general perspective for auditing," Auditing: A Journal of Practice and Theory 9 (Supplement), (1990), 110-48.

[9] Shenoy, P.P., and G. Shafer, "An axiomatic framework for bayesian and belieffunction propagation," Proceedings of the Fourth Workshop on Uncertainty in Artificial Intelligence. St. Paul, MN: AAAI Press, 1988, 307-14.

[10] Shenoy, P.P., and G. Shafer, "Axioms for probability and belief-function propagation," In Uncertainty in Artificial Intelligence 4, edited by R. D. Shachter, et al. Amsterdam: North-Holland, 1990, 169-98.

[11] Srivastava, R. P., "Belief Functions and Audit Decisions," Auditors Report, 17, (Fall 1993), 8-12.

[12] Srivastava, R. P., "A General Scheme for Aggregating Evidence in Auditing: Propagation of Beliefs in Networks," Artificial Intelligence in Accounting and Auditing, Vol. 3, Edited by Miklos A. Vasarhelyi, Markus Wiener Publishers, Princeton, 1995a, 55-99. 
[13] Srivastava, R. P., "The Belief-Function Approach to Aggregating Audit Evidence" International Journal of Intelligent Systems, (March 1995b), 329-356.

[14] Srivastava, R. P., "An 'AND-NEOR' Node for Propagating Beliefs in a Network of Variables with Linear Algebraic Relationships," Working Paper. School of Business, The University of Kansas, 1997.

[15] Srivastava, R. P. and K. Cogger, "Algorithm for Determining m-values on the Joint Space of the Variables from Belief Functions Defined on Each Variable," Working Paper, School of Business, The University of Kansas, Lawrence, Kansas, 1995.

[16] Srivastava, R. P., S. Dutta, and R. Johns, "An Expert System Approach to Audit Planning and Evaluation in the Belief-Function Framework," International Journal of Intelligent Systems in Accounting, Finance and Management, 5, (1996) 165-183.

[17] Srivastava, R. P. and G. Shafer, "Belief-Function Formulas for Audit Risk," The Accounting Review, 67, (April, 1992), 249-283.

[18] Srivastava, R. P., P. Shenoy, and G. Shafer, "Propagating Beliefs in an 'AND' Tree," International Journal of Intelligent Systems, 10, (1995) 647-664. 



\section{Figure 1}

Evidential Network for Accounts Receivable for a Health Care Unit with “And” Relationship among Variables. Subroutines 1-7 are given in Figures 1a-1c. (Source: Srivastava, Dutta, and Johns 1996).

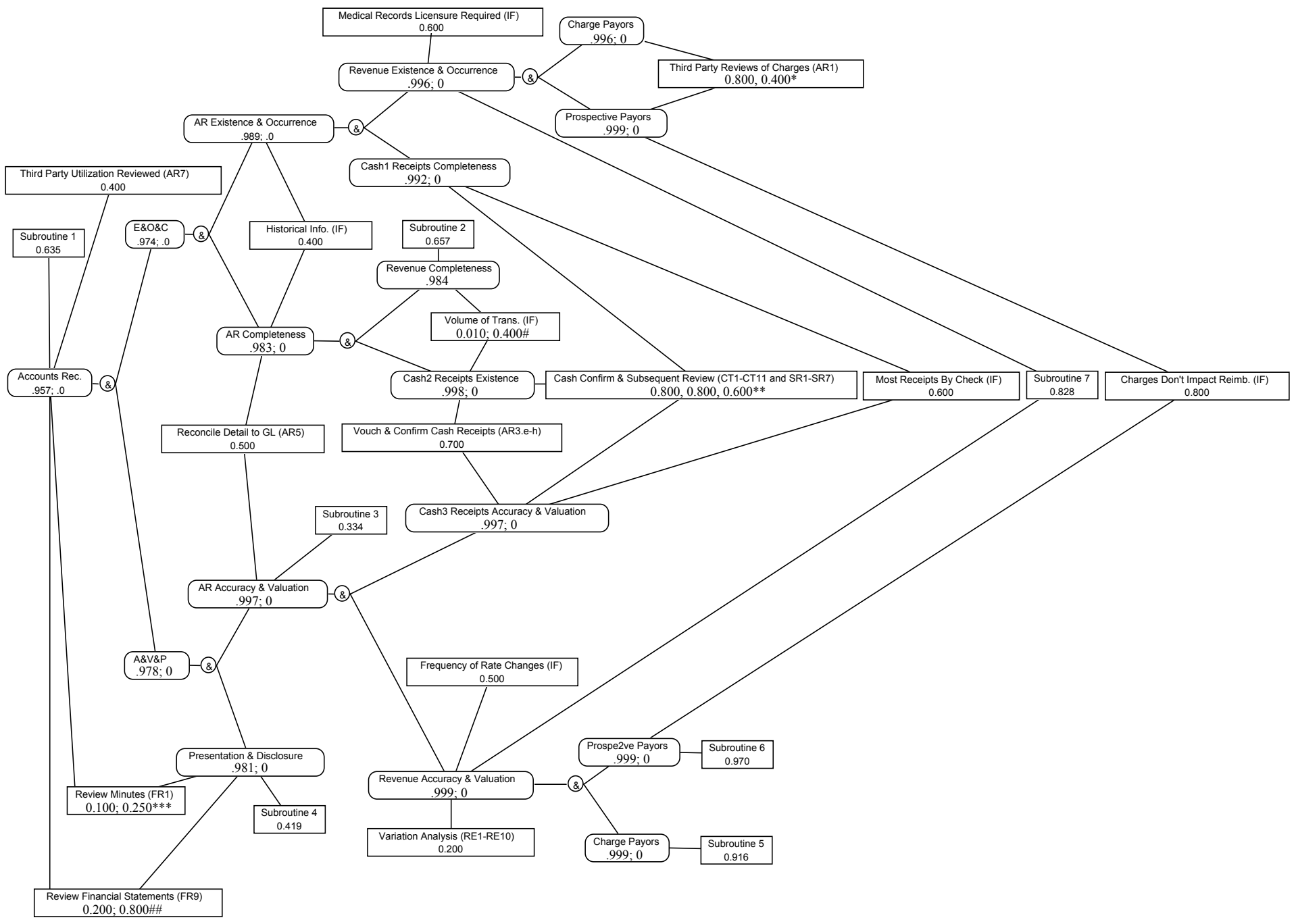

*0.8, and 0.4 levels of support to 'Prospective Payers' and 'Charge Payers', respectively, that they are met. Similarly the following levels of support imply that the corresponding objective has been met: **0.8, 0.8, and 0.6, respectively, for 'Cash Receipts Completeness', 'Cash Receipts Existence', and 'Cash Receipts Accuracy \& Valuation'; *** 0.1 , and 0.25 , respectively, for 'Accounts Rec.', and 'Presentation and Disclosure'; \#0.01, and 0.4, respectively for 'Revenue Completeness', and 'Cash Receipts Existence'; \#\#0.2, and 0.8, respectively, for 'Accounts Rec.', and 'Presentation and Disclosure'. 


\section{Figure 1b}

Subroutines 4 and 5 used in Figure 1. (Source: Srivastava, Dutta, and Johns 1996)
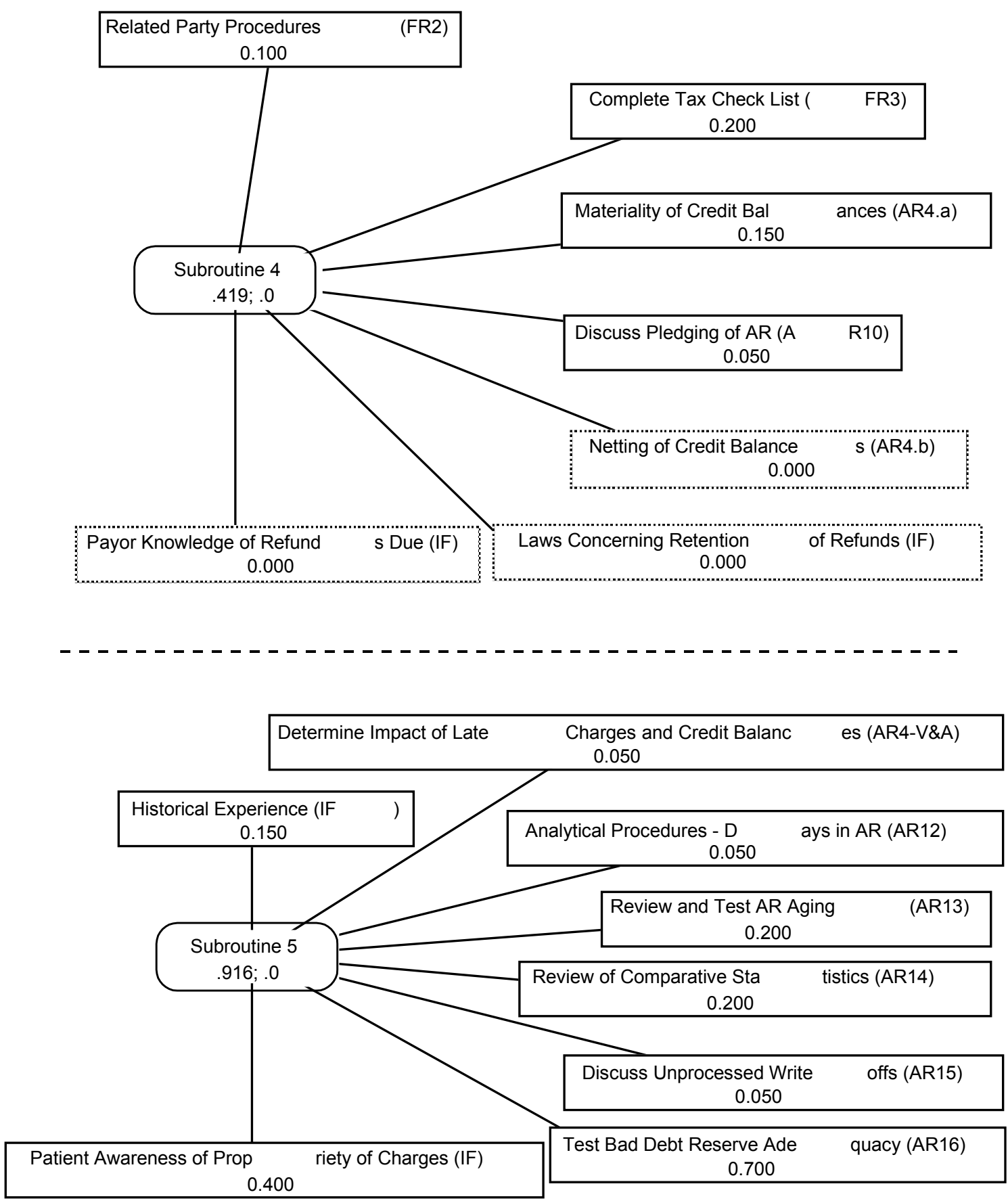


\section{Figure 1c}

Subroutines 6 and 7 used in Figure 1. (Source: Srivastava, Dutta, and Johns 1996).
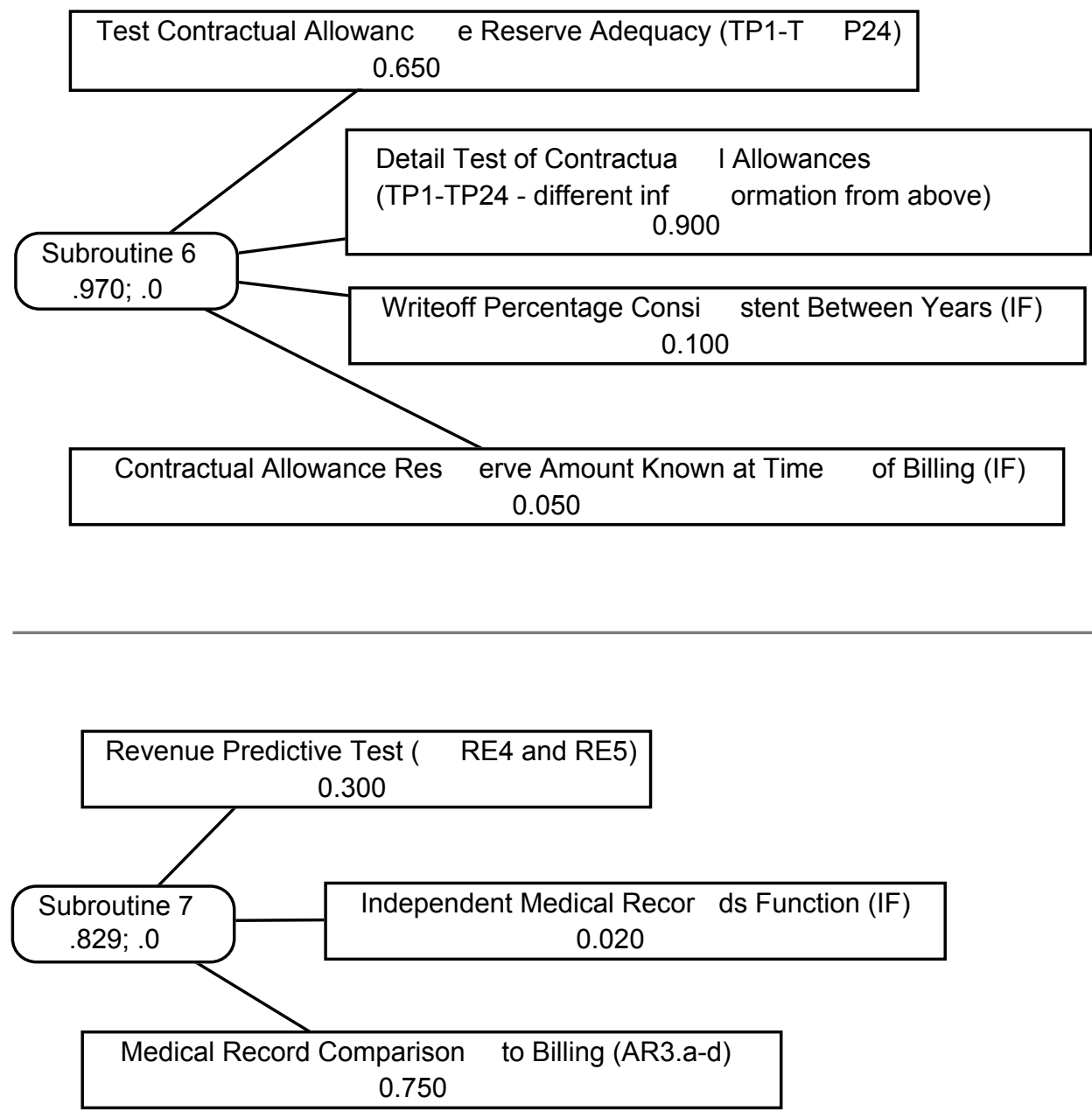
Figure 2

Tree Structure of Evidence for Accounts Receivable for a Health Care Unit with "And” Relationship among Variables. Subroutines 1-7 are given in Figures 1a-1c. (Source: Srivastava, Dutta, and Johns 1996).

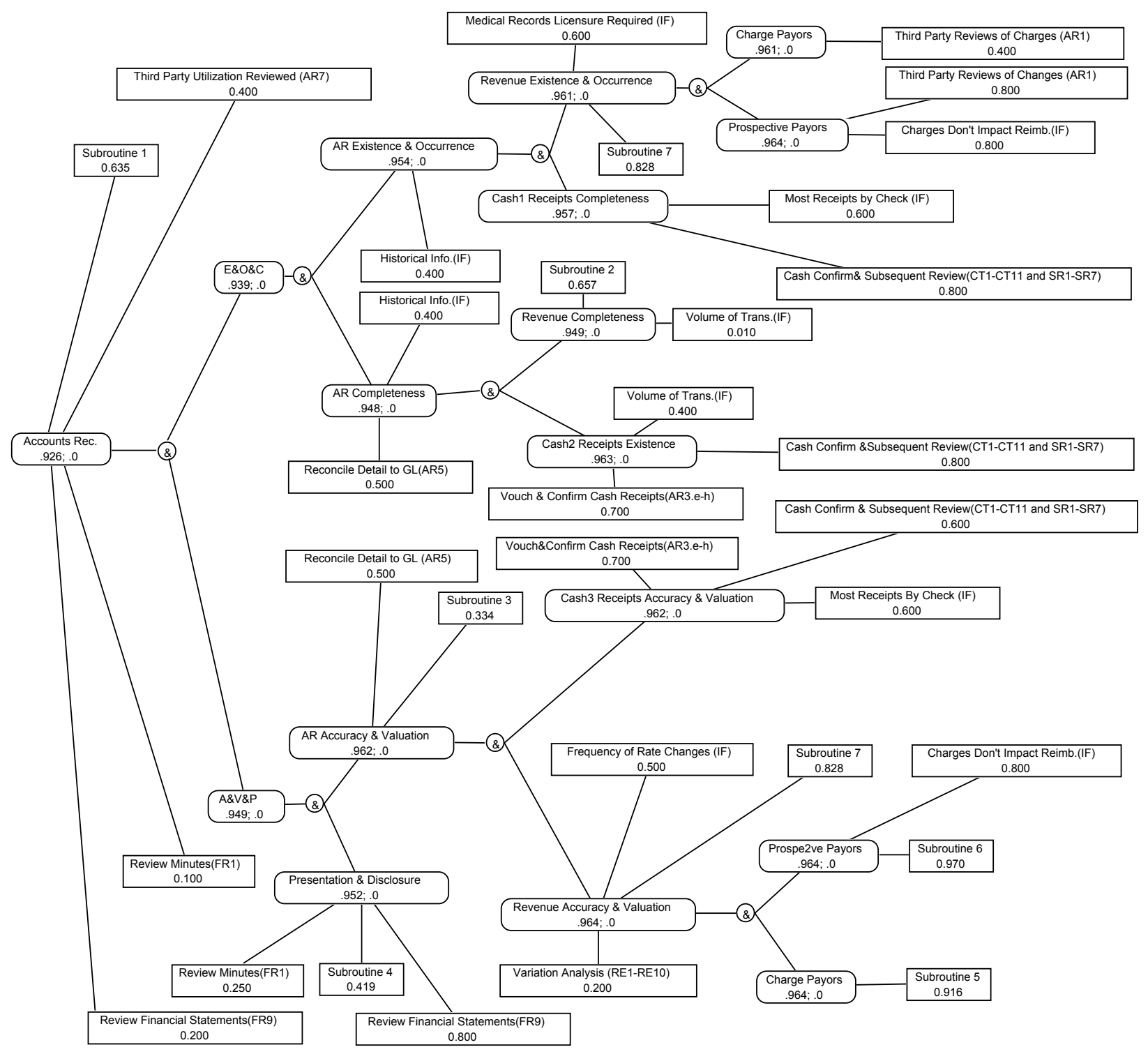


Figure 3

Percentage Change in Overall Belief with the Changes in the Strength of all the Evidence from a Network Structure to a Tree Structure with 'And' Nodes.

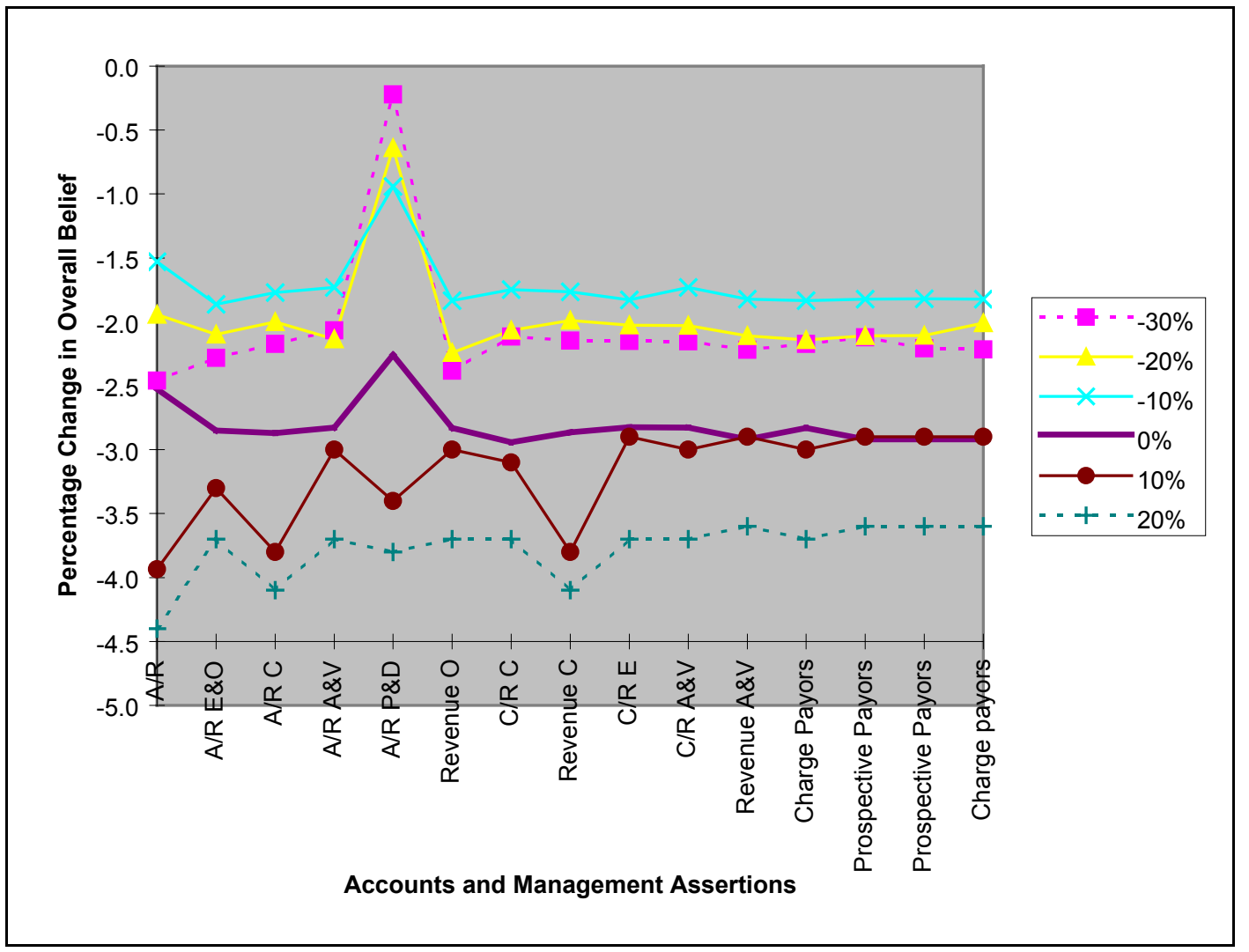

Figure 4

Percentage Change in Overall Belief with the Changes in the Strength of all the Evidence from a Network Structure to a Tree Structure with 'And-Neor' Nodes.

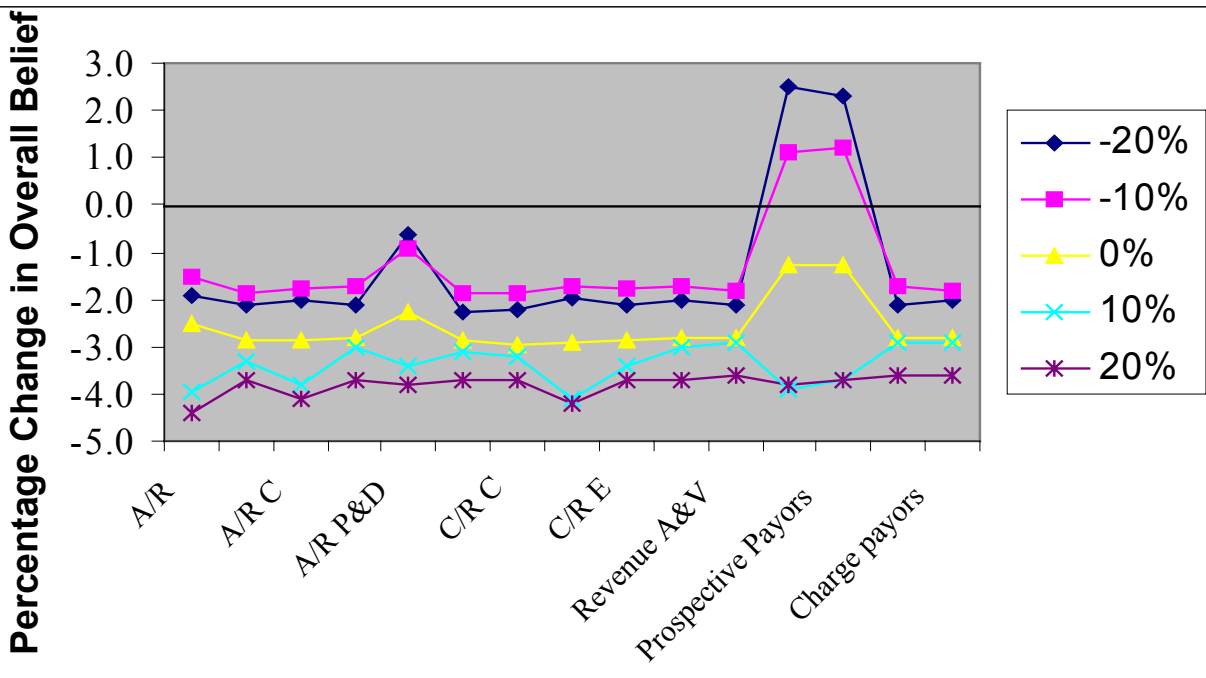

Accounts and Management Assertions 
Figure 5

Percentage Change in Overall Belief from a Network Structure to a Tree Structure with 'And' Nodes as Additional Items of Evidence are Obtained Starting From Account Level to Sub-transaction level.

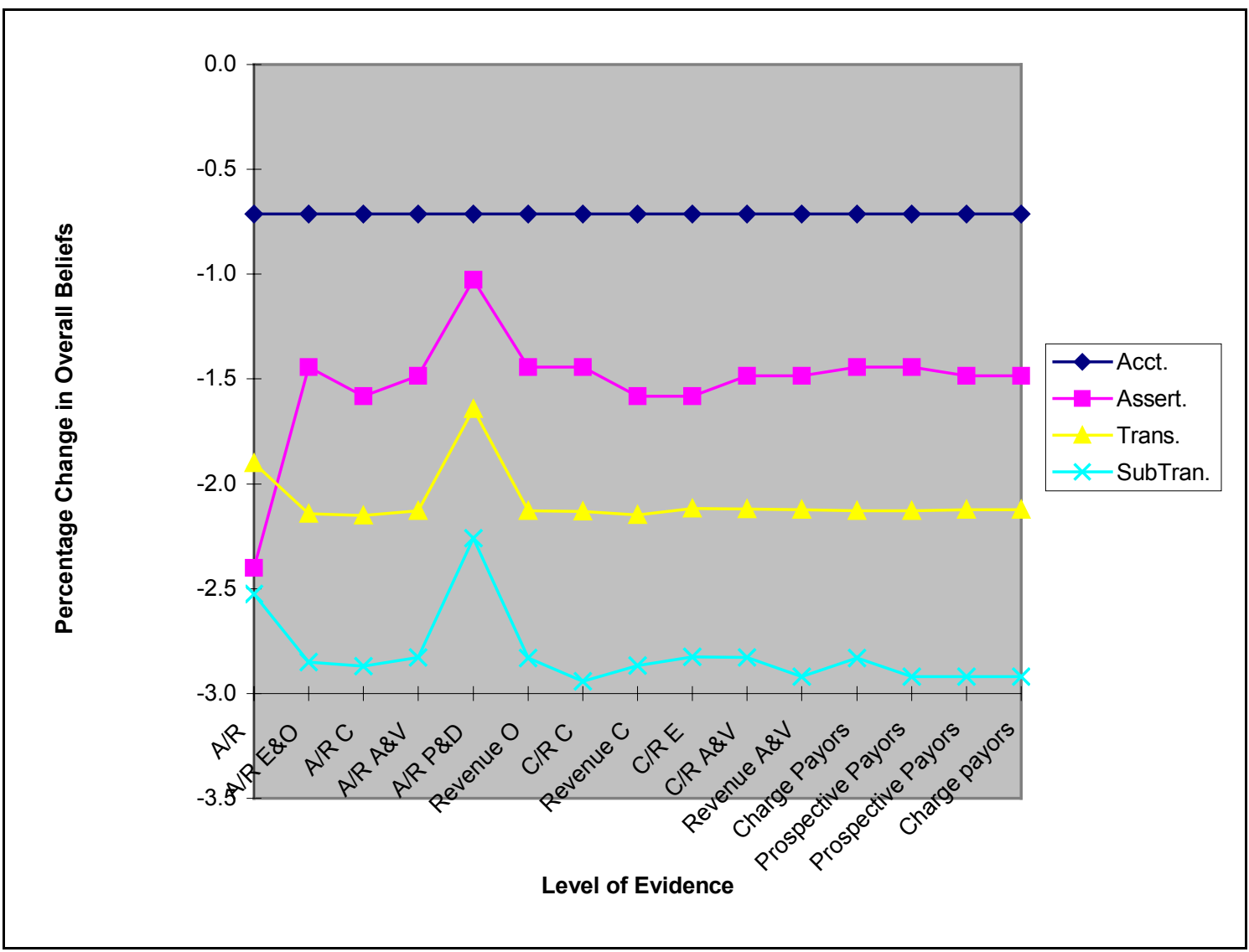



Table 1

Overall Beliefs for Network Structure with 'And' and 'And-neor' Relationships.

\begin{tabular}{|c|c|c|c|c|c|c|c|c|c|c|c|c|c|c|c|}
\hline & \multicolumn{3}{|c|}{$-20 \%$} & \multicolumn{3}{|c|}{$-10 \%$} & \multicolumn{3}{|c|}{$0 \%$} & \multicolumn{3}{|c|}{$10 \%$} & \multicolumn{3}{|c|}{$20 \%$} \\
\hline & And & $\begin{array}{l}\text { And- } \\
\text { neor }\end{array}$ & Change & And & $\begin{array}{l}\text { And- } \\
\text { neor }\end{array}$ & Change & And & $\begin{array}{l}\text { And- } \\
\text { neor }\end{array}$ & Change & And & $\begin{array}{l}\text { And- } \\
\text { neor }\end{array}$ & Change & And & $\begin{array}{l}\text { And- } \\
\text { neor }\end{array}$ & Change \\
\hline \multicolumn{16}{|l|}{ Account Level } \\
\hline Accounts Receivable & 0.875 & 0.875 & 0.000 & 0.915 & 0.915 & 0.000 & 0.950 & 0.950 & 0.000 & 0.991 & 0.991 & 0.000 & 1.000 & 1.000 & 0.000 \\
\hline \multicolumn{16}{|l|}{ Objective Level } \\
\hline $\begin{array}{l}\text { AR Existence \& } \\
\text { Occurrence }\end{array}$ & 0.953 & 0.953 & 0.000 & 0.966 & 0.966 & 0.000 & 0.982 & 0.982 & 0.000 & 1.000 & 1.000 & 0.000 & 1.000 & 1.000 & 0.000 \\
\hline AR Completeness & 0.949 & 0.949 & 0.000 & 0.960 & 0.960 & 0.000 & 0.976 & 0.976 & 0.000 & 1.000 & 1.000 & 0.000 & 1.000 & 1.000 & 0.000 \\
\hline AR Accuracy \& Valuation & 0.983 & 0.983 & 0.000 & 0.982 & 0.982 & 0.000 & 0.990 & 0.990 & 0.000 & 1.000 & 1.000 & 0.000 & 1.000 & 1.000 & 0.000 \\
\hline Presentation \& Disclosure & 0.939 & 0.939 & 0.000 & 0.955 & 0.955 & 0.000 & 0.974 & 0.974 & 0.000 & 1.000 & 1.000 & 0.000 & 1.000 & 1.000 & 0.000 \\
\hline \multicolumn{16}{|l|}{ Transaction Level } \\
\hline $\begin{array}{l}\text { Revenue Existence \& } \\
\text { Occurrence }\end{array}$ & 0.981 & 0.964 & 1.763 & 0.981 & 0.973 & 0.822 & 0.989 & 0.986 & 0.304 & 1.000 & 1.000 & 0.000 & 1.000 & 1.000 & 0.000 \\
\hline $\begin{array}{l}\text { Cash Receipts } \\
\text { Completeness }\end{array}$ & 0.967 & 0.951 & 1.682 & 0.973 & 0.966 & 0.725 & 0.986 & 0.983 & 0.305 & 1.000 & 1.000 & 0.000 & 1.000 & 1.000 & 0.000 \\
\hline Revenue Completeness & 0.955 & 0.912 & 4.715 & 0.963 & 0.939 & 2.556 & 0.977 & 0.966 & 1.139 & 1.000 & 0.999 & 0.100 & 1.000 & 1.000 & 0.000 \\
\hline Cash Receipts Existence & 0.987 & 0.945 & 4.444 & 0.985 & 0.961 & 2.497 & 0.991 & 0.980 & 1.122 & 1.000 & 1.000 & 0.000 & 1.000 & 1.000 & 0.000 \\
\hline $\begin{array}{l}\text { Cash Receipts Accuracy \& } \\
\text { Valuation }\end{array}$ & 0.985 & 0.982 & 0.305 & 0.983 & 0.982 & 0.102 & 0.990 & 0.990 & 0.000 & 1.000 & 1.000 & 0.000 & 1.000 & 1.000 & 0.000 \\
\hline $\begin{array}{l}\text { Revenue Accuracy \& } \\
\text { Valuation }\end{array}$ & 0.995 & 0.992 & 0.302 & 0.988 & 0.987 & 0.101 & 0.993 & 0.992 & 0.101 & 1.000 & 1.000 & 0.000 & 1.000 & 1.000 & 0.000 \\
\hline \multicolumn{16}{|l|}{ Sub-Transaction Level } \\
\hline \multicolumn{16}{|c|}{ Revenue Existence \& Occurrence: } \\
\hline Charge Payers & 0.981 & 0.841 & 16.647 & 0.981 & 0.898 & 9.243 & 0.989 & 0.947 & 4.435 & 1.000 & 1.000 & 0.000 & 1.000 & 1.000 & 0.000 \\
\hline Prospective Payers & 0.995 & 0.869 & 14.499 & 0.988 & 0.911 & 8.452 & 0.993 & 0.953 & 4.197 & 1.000 & 1.000 & 0.000 & 1.000 & 1.000 & 0.000 \\
\hline \multicolumn{16}{|c|}{ Revenue Accuracy and Valuation: } \\
\hline Prospective Payers & 0.997 & 0.990 & 0.707 & 0.989 & 0.986 & 0.304 & 0.993 & 0.992 & 0.101 & 1.000 & 1.000 & 0.000 & 1.000 & 1.000 & 0.000 \\
\hline Charge payers & 0.995 & 0.986 & 0.913 & 0.988 & 0.985 & 0.305 & 0.993 & 0.992 & 0.101 & 1.000 & 1.000 & 0.000 & 1.000 & 1.000 & 0.000 \\
\hline
\end{tabular}


Table 2

Overall Beliefs for Tree Structure with 'And' and 'And-neor' Relationships.

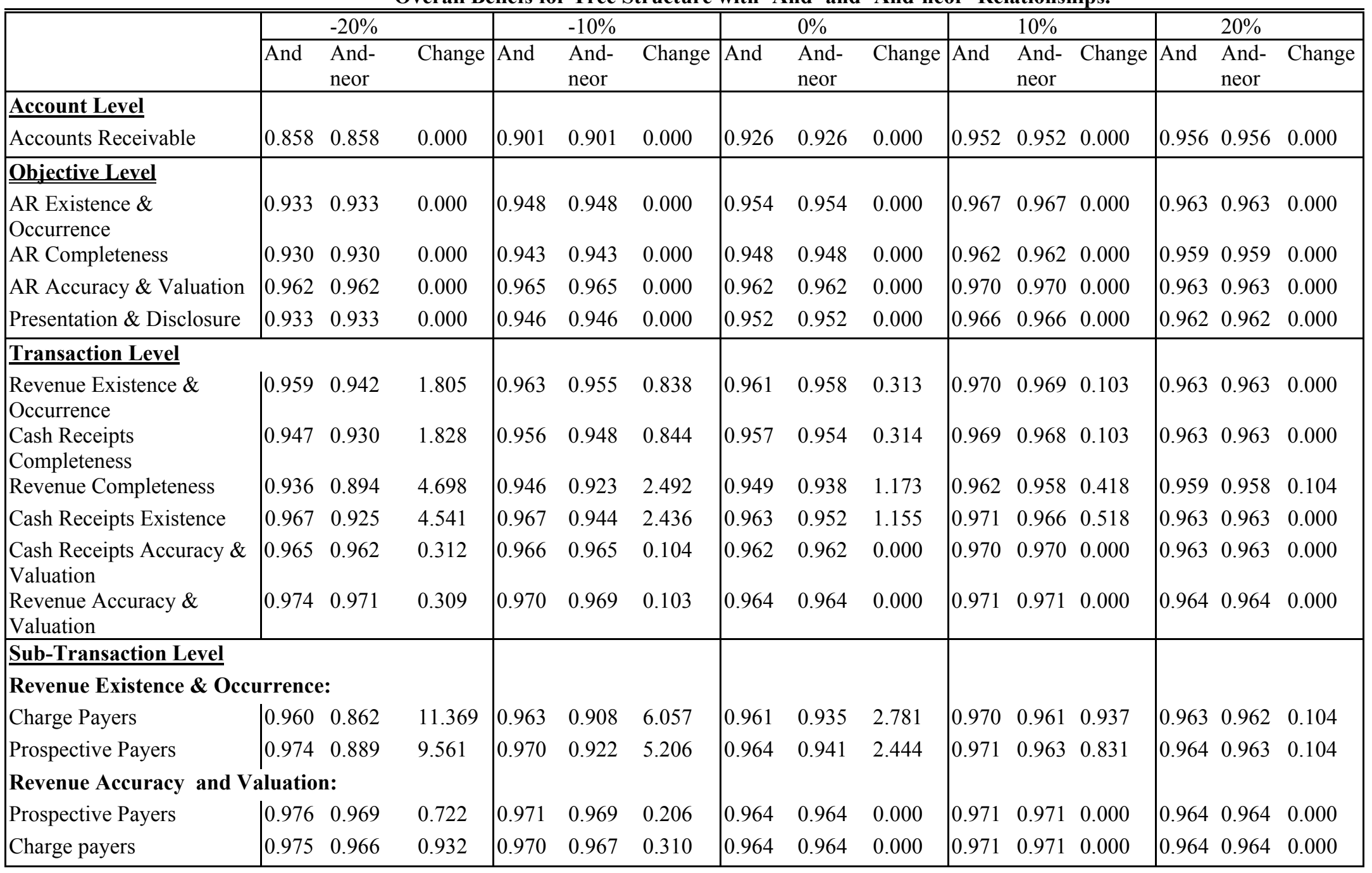


